\title{
Rescheduling of Wet Season (T. Aman) Rice Planting for Cropping Intensification in Coastal Bangladesh ${ }^{+}$
}

\author{
Md. Maniruzzaman 1,*, Mohammed Mainuddin 2, Richard Bell 3, Jatish Chandra Biswas ${ }^{1}$, \\ Md. Jahangir Kabir ${ }^{1}$, Md. Belal Hossain ${ }^{1}$, Mst. Shetara Yesmin ${ }^{1}$, A. B. M. Mostafizur ${ }^{1}$ and \\ Palash Kumar Kundu ${ }^{1}$ \\ 1 Bangladesh Rice Research Institute (BRRI), Gazipur 1701, Bangladesh; mzamaniwm@yahoo.com (M.M.); \\ jatishb@yahoo.com (J.C.B.); jahangir.kabir@uq.net.au (M.J.K.); belal.iwm@gmail.com (M.B.H.); \\ shetara.brri.bd@gmail.com (M.S.Y.); abmm.brri@gmail.com (A.B.M.M.); kundu22_bau@yahoo.com (P.K.K.) \\ 2 Commonwealth Scientific and Industrial Research Organisation (CSIRO), Canberra 2601, Australia; \\ mohammed.mainuddin@csiro.au \\ 3 School of Veterinary and Life Sciences, Murdoch University, Parth 6150, Australia; r.bell@murdock.edu.au \\ * Correspondence: mzamaniwm@yahoo.com; Tel.: +880-15-5232-8965 \\ + Presented at the Third International Tropical Agriculture Conference (TROPAG 2019), Brisbane, Australia, \\ 11-13 November 2019.
}

Published: 2 January 2020

\begin{abstract}
About 1.0 million ha coastal lands in Bangladesh are mono-cropped suffer from varying degree of soil salinity, waterlogging and climate vulnerability. Low yielding, traditional T. Aman rice is grown only in wet season. Growing non-rice crop after late harvested T. Aman rice is not profitable. This study was aimed to introduce high yielding, short duration T. Aman rice varieties for advancing its harvesting time and to make the avenue for timely establishment of dry season crops. Varietal trials were made at Dacope and Amtali under ACIAR funded project during 20162018 and compared with local cultivars. Among tested varieties BRRI dhan76 followed by BRRI dhan77 and BRRI dhan54 in Dacope and BRRI dhan77 followed by BRRI dhan76 and BRRI dhan54 in Amtali were preferred for $0.5-1.0$ tha $^{-1}$ yield advantage and 15-25 days earliness compared to traditional varieties. Early harvesting of $\mathrm{T}$. Aman created the avenue of timely establishment of rice and non-rice crops depending on availability of fresh water and thus crop intensification and land productivity was improved. The new cropping system increased annual rice yield and farmers' profits by 1.5- to 2 -folds compared with traditional system without environmental degradation. This technique can be replicated in similar coastal zones of Bangladesh.
\end{abstract}

Keywords: T. Aman rice; crop intensifications; early harvest; coastal zones; Bangladesh

Funding: This study was funded by the Australian Centre for International Agricultural Research (ACIAR), Australia and Krishi Gobeshona Foundation (KGF), Bangladesh.

Acknowledgments: The study was conducted under the fund support of ACIAR, Australia and KGF, Bangladesh under the supervision of Commonwealth Scientific and Industrial Research Organization (CSIRO) and Murdock University, Australia and Bangladesh Rice Research Institute (BRRI), Bangladesh through the project, entitled "Cropping system intensification in the salt affected coastal zones of Bangladesh and West Bengal, India".

Conflicts of Interest: The authors declare no conflict of interest.

(C) 2020 by the authors. Licensee MDPI, Basel, Switzerland. This article is an open access article distributed under the terms and conditions of the Creative Commons Attribution (CC BY) license (http://creativecommons.org/licenses/by/4.0/). 